\title{
Effects of Change Management Strategies on Performance in National Examinations in Public Secondary Schools in Kisii County, Kenya
}

\author{
Francis Onyoni Chieta ${ }^{1}$ (JKUAT Kisii CBD Campus), Dr. Walter Okibo ${ }^{2}$ \\ (JKUAT, Main Campus), James Ondieki Ratemo ${ }^{3}$ (Kisii University), Wilter \\ Bosibori Nyamwamu ${ }^{4}$ (JKUAT Kisii CBD Campus) \& Gitau Beth Njeri ${ }^{5}$ \\ (School of Agriculture, Rongo University College) \\ Francis Onyoni Chietal (JKUAT Kisii CBD Campus), Dr. Walter Okibo ${ }^{2}$ (JKUAT, Main Campus), James \\ Ondieki Ratemo ${ }^{3}$ (Kisii University), Wilter Bosibori Nyamwamu ${ }^{4}$ (JKUAT Kisii CBD Campus) \& Gitau Beth \\ Njeri $^{5}$ (School of Agriculture, Rongo University College)
}

\begin{abstract}
Management and performance in secondary schools is dismal as management and discipline are wanting. This study assessed the effect of change management strategies on performance in national examinations. The study objectives were: to assess the performance of secondary schools in KCSE examination in Kisii County, to identify the extent motivation, leadership and benchmarking strategies of change management are adopted in secondary schools and establish the relationship between change management strategies and performance in National Examinations by secondary schools in Kisii County. This study was based on Goal theory of motivation. This study adopted a survey design. The study target population was 750 respondents in secondary schools in Kisii County. The study sample was 88 respondents. Stratified random sampling technique was applied to select a sample for this study. Quantitative data collected was analyzed using descriptive statistics and inferential statistics and a 5 Point-Likert Scale. The findings of the study include: the implementation of realistic, achievable and measurable issues, leadership styles and benchmarking were the key strategies that were used were influential on the performance in National Examinations in Kisii County. Recommendations: schools should embrace the use of motivation, benchmarking and good leadership styles to achieve the higher level of performance in national examinations.
\end{abstract}

Keywords: Change Management Strategies, Performance, National Examinations

\section{Introduction}

For the past few years a great proportion of learners have performed badly in the national examinations. For example, in the Nyanza Province the pass rates were low (Riekert, 2000). All major stakeholders: learners, educators, parents, employers and the National Ministry of Education are concerned about the problem of poor student performance in national examinations in Kenya. This low internal efficiency of the education system simply implies more wastage and increases in the cost of education. By failing to complete their high school education within the minimum time, the social cost of secondary education increases without necessarily increasing the social benefits. The consequences lead to social costs of billions. Poor student performance in national examinations represents a challenge to all Kenyans (OECD, 2000).

Most indicators are designed to monitor the broad context within which a policy operates; provide benchmark measurements against the specified goals; forecast the emergence or existence of new problems; and permit development of systems explanations for existing problems; all these issues influence performance(OECD, 2000). Policy makers, practitioners, and the general public can use the indicators to evaluate the performance of the education system and to inform decisions about educational priorities and directions. Drop-out and survival rates can be useful indicators of the internal efficiency of the education systems. Although dropping out is not necessarily an indication of failure by individual students, high drop-out rates may well indicate that the education is not meeting the needs of the clients(Riekert, 2000). Dropping out of school represents a waste of human and financial resources, unless students acquire basic skills during their time of study.

Public sector organisations are often perceived as resisting change; many seek capacity to get things done but not change. The introduction of increased use of appropriate change management strategies and methods in development cooperation will often be resisted due the difficulty of precise definition of their results and the uncertainty of their outcomes. For many development practitioners change and capacity are distinct, but the evidence suggests that they are intertwined (Senge, 1999). It is important to understand what aspects of the status quo can be changed so that capacity development can take place. Identifying the boundaries of change 
management work is important as is identifying the risks and potential mitigation (Pascale, 1999). Institutional change is hard to conceptualize for public sector organizations and harder to apply.

Organizational leaders tasked with managing change are engaged in 'a great venture of exploration, risk, discovery and change without any comprehensive maps for guidance', that is, mapping of change management process steps and ensuring it is consulted on widely, disseminated and agreed to, is key to its relevance and effectiveness. Beyond a mapping of steps, guiding the process step-by-step is critical to its success, with internal champions playing the primary role and facilitated by process facilitators as required (Senge, 1999).

Change efforts are significantly normative in nature. Positive change is driven by coalitions of aligning interests, soft systems like motivation, ethics and pride and fundamental transformational issues starting with individual transformation in attitudes, values and behaviour. Cultural and value issues often dictate change outcomes. The ability to engineer and construct change through shop floor processes, while valid, still remains somewhat limited in its reach and most change occurs more in the realm of behaviour, ethics, values, softsystems incentives. According to the United Nations Human Rights Watch (2001), education is the single most vital element in combating poverty, empowering women, protecting children from hazardous and exploitative labour and sexual exploitation, promoting human rights and democracy, protecting the environment and influencing population growth. Education is a path towards international peace and security.

The ministry of education report (July, 2008), indicated that some strikes in public schools is triggered by management change particularly in the provision of essential services. Among the strategies applied in instilling discipline on learners is corporal punishment. According to Oyaro (1997), the research findings indicated that corporal punishment impacted on the psychological and intellectual development of students; this study failed to make clarity on whether this punishment could have any measurable influence on academic performance of the learners in the school.

According to Drew (2011), serving effectively in a company's management arm is a complex and multi-layered assignment. Managers must supervise workers, serve as liaisons between employers and employees, interact with vendors and represent the company to the outside world. This requires organizational knowledge, the ability to communicate effectively and strong multi-tasking skills. Strategies for success to overcome management barriers include strategic flexibility and rigidity. In strategic flexibility involves identifying external factors that might incite change within a business, allocating resources to address those potential threats and acting quickly to fine-tune current strategies to better accommodate these shifts; one strength associated with strategic flexibility as a management strategy is that it allows managers to make adjustments to goals and resource allocations to address ever-changing circumstances rather than blindly adhering to outdated or irrelevant plans and goals (Oyaro, 1997).

According to Drew (2011), management rigidity can be thought of as resisting the temptation to change policies, plans or strategies in the face of shifting needs and external factors. It prevents the constant changing of plans and strategies that could cause a company to lose focus, bringing more stability to a business; its strength is that it decreases the chances that an inexperienced manager will not create and pursue ineffective new strategies to address challenges rather than holding the course. Rigidity can be devastating to a business, however. Ignoring changing circumstances can render a business irrelevant or unsuccessful in evolving markets. Moreover lack of accountability can give managers excessive control, operating without oversight and perhaps stirring employee resentment. If employers value short-term performance goals, long-term managerial development can be impeded because there is not time or resource allocation that can help managers increase skills. Another barrier to management development is resistance to embracing a multicultural or diverse workplace environment. This causes an unwillingness to recognize the potential of employee problem-solving and perspective, and can cause internal conflict among workers (Drew, 2011).

\section{Statement of the Problem}

Managers use the management strategies as levers of strategic change to influence performance. This question is interesting both from a theoretical and a practical viewpoint. Kotter and experts on the subject of change management began writing about change management back in the mid-1990s, when he first declared that only one change initiative in three actually achieved its stated objectives. McKinsey et.al., (2008) conducted a global survey of change management and found just about the same results as Kotter had 12 years before, only a third of change management attempts are successful. It is observed that the performance in schools has been fluctuating over the years among secondary schools in Kisii County. The fluctuating performance has been pegged on the change management strategies embraced by the schools. The role of change management is brought about to bring in strategies to counter the effects of poor performance. It is not clear to what extent the strategies of change are utilized for their effects to influence performance. This study (seeks to delete) assessed the effects of change management strategies on the performance in national examinations by schools in Kisii County, Kenya. 


\section{Objectives of the Study}

The general objective was to investigate if leadership styles, motivation and benchmarking as change management strategies do influence performance in National Examinations. The specific objectives were:

i) To identify the extent motivation strategies of change are adopted in secondary schools

ii) To identify the extent leadership strategies of change are adopted in secondary schools

iii) To identify the extent benchmarking strategies for change are adopted in secondary schools

iv) To establish the extent to which leadership, motivation and benchmarking strategies do influence performance in National examinations by secondary schools in Kisii County.

\section{Significance of the Study}

The study findings on benchmarking may be important tools in realizing improved performance. The school managers may consider the objectives to be achieved, time and resources available and compatibility of best practices to a school's processes before embarking on a benchmarking exercise. Parents may also be requested to cooperate and support school programmes. To the Ministry of Education the findings may help them come up with a formal structure, which could assist school managers to systematically and continuously adopt best practices for high performance in schools. This may eventually lead to improved performance of students in national examinations.

The findings may further be helpful to the Ministry of Education in reshaping the policies related to change management in the public secondary schools in Kenya. It is also important to employers and organizations that may be concerned with learner's performance. The management of the public secondary schools should put in place strategies to employ, retain a suitable strategies for purposes of working towards realizing the educational goals. To research students the information obtained can bridge the gap between the researched work and un-researched areas. This can enhance career growth and good performance in various leaning institutions

\section{Conceptual Framework}

The study employed a conceptual framework. It shows that change management strategies have a direct relationship to the academic performance of the students in National examinations. The leadership styles of head teachers influence school performance of secondary schools in Kenya. The relationship between the two variables was investigated in order to determine the strength of their relationship and the coefficients of determination existing between them.

Independent Variable (s)

Figure 1: Conceptual Framework

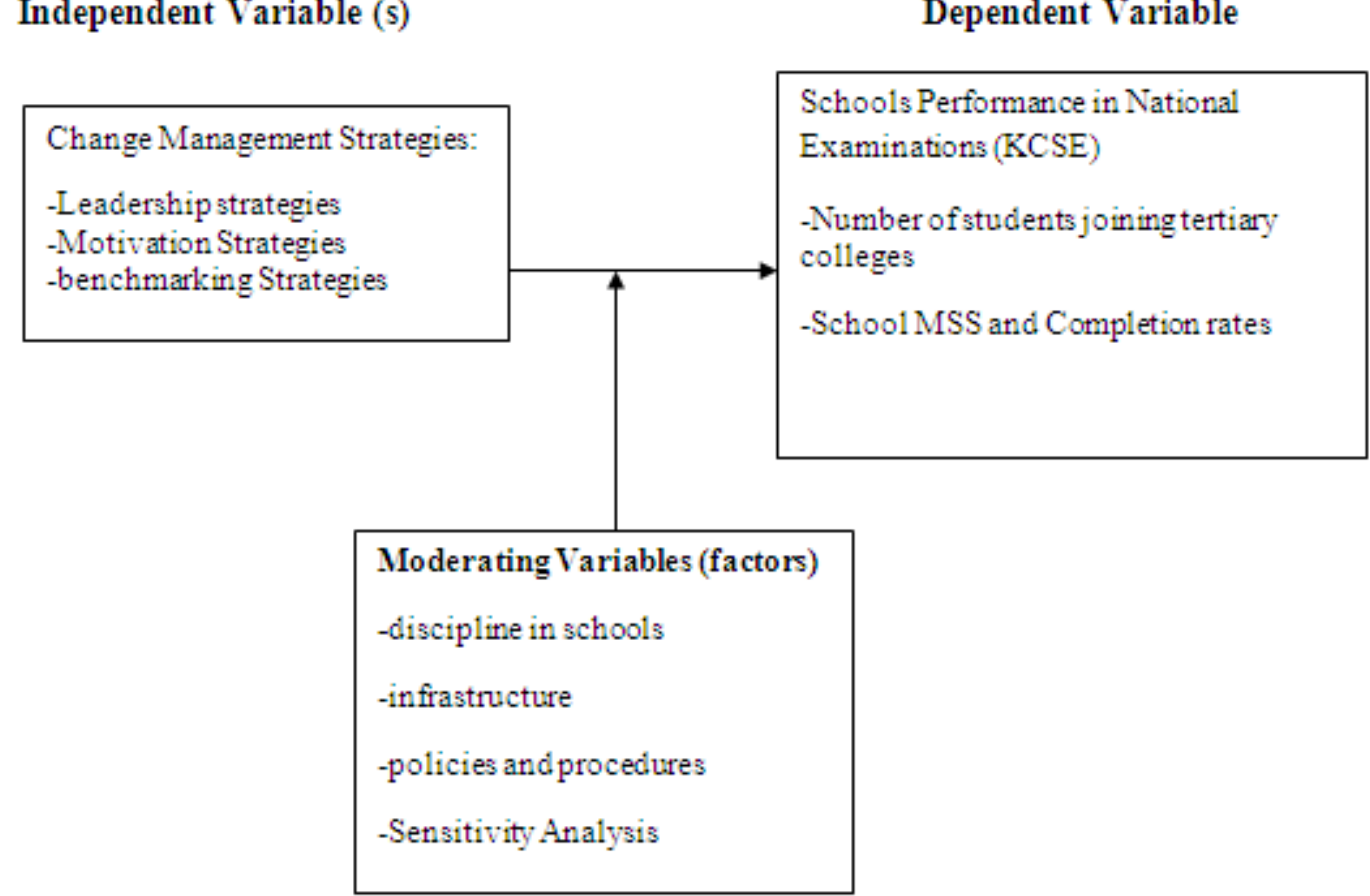

VI. Research Methodology 


\section{Research Design}

This study adopted a descriptive survey. A survey study is used when collecting information from members of a population in order to determine the current state of affairs as they exist in that population with respect to one or more variables (Orodho and Kombo, 2002). The intention of this survey research was to gather data at a particular point in time and use it to describe the nature of existing conditions and this study assessed the relationship between the variables: change management strategies and performance in KCSE by secondary schools in Kisii County.

\section{Target Population}

The study target population was 750 respondents consisting of 150 head teachers and 600 head of departments in the secondary schools in Kisii County

\section{Sample Size And Sampling Design}

The study sample size was determined by adopting the scientific formulae by Nassiuma (2000):

Sample size $(n)=\left\{\mathrm{NCv}^{2}\right\} /\left\{\mathrm{C}_{\mathrm{v}}{ }^{2}+(\mathrm{N}-1) \mathrm{e}^{2}\right\}$

Where:

$\mathbf{N}$ is the target population (750)

$\mathbf{c}_{\mathbf{v}}$ is the coefficient of variation (take 0.5 )

e- tolerance at desired level of confidence, at $95 \%$ confidence level (take 0.05) $\mathbf{n}$

$=\left\{\mathbf{N ~ C}_{\mathrm{v}}^{2}\right\} /\left\{\mathbf{C}_{\mathrm{v}}^{2}+(\mathbf{N}-1) \mathrm{e}^{2}\right\}$

$=\left\{750 \times 0.5^{2}\right\} /\left\{0.5^{2}+(750-1) 0.05^{2}\right\}$

$=187.5 / 2.1225,=88$ respondents

Thus the study sample size consisted of 88 respondents. The sampling procedure adopted in this study was simple random sampling technique to select a sample for this study.

\section{Data Collection Instrument}

A structured questionnaire was used for data collection. The instrument was given to the respondents who reacted to the questions in the research instrument for this study.

\section{Reliability of the Instruments}

Reliability of the questionnaire was determined by test-retest method in the region of study by using respondents who were not be part of the study sample but in the positions relevant to the research study. Reliability is the ability of the instruments to provide consistent information in order to draw informed conclusions.

\section{Data Analysis}

Quantitative data collected was analyzed using descriptive and inferential statistics. Descriptive statistics was used to summarize the data in form of frequency tables. A 5- point Likert scale was used to assess the strength of the variables in the study. Simple regression analysis was used and Pearson's correlation coefficient was determined that assessed the degree of association between the variables in this study.

\section{Discussion of Findings and Recommendations}

The study established that majority of the respondents were of male gender. Hence there is gender imbalance in most of the public schools in Kenya, particularly those in Kisii County. Further it was established that $32.9 \%$ (29) of the total respondents were aged 41 to 45 years and formed the majority of the age structure population among the teachers involved in strategic change management in schools in Kisii County.

The study found out that $61.4 \%$ (54) of the total respondents were holders of degree level of education in Kisii County. The research further found out that 52.3\% (46) of the total respondents have served in their current stations for a duration between 9 to 15 years hence their structures of strategy development and change management process if any they have seen complete the Plan -Do-Check - Act Cycle in their respective schools as learners do pass through schools education system in four years.

The study established that respondents majority of them $52.3 \%$ (46) serve in the disciplinary department (committees). This committee is important as is part of strategy setting team in any school. Therefore education success entirely depends on the level of discipline observed by the learners. The study further found out that teachers, parents and Board of Management form the basis of any institution's success; their contribution play a vital role in change management. 
The study further found out that the implementation of realistic, achievable and measurable issues, thoughtful planning and stakeholder participation through consultation; creation of ownership of strategies set to achieve the objectives were key issues incorporated moderately as propellers' of change management in the public institutions in Kisii County.

The study established that a number of motivation strategies were adopted towards achieving change management in the schools; flexibility in programs, empowering of teachers, effective reward system geared to change management were all adopted to influence the achievement of change management objectives in public institutions in Kisii County.

The study established that motivation, leadership styles and benchmarking were the key strategies that were used in the secondary schools in Kisii County to influence change towards achieving better performance. A 5- point Likert scale was used which indicated the range of strengths; motivation strategies facilitated change more to a great extent (4.409), benchmarking (at 4.318 strength) and leadership styles to a moderate extent (3.784). The study further established that motivation and leadership strategies were influential on the performance in national examinations in Kisii County.

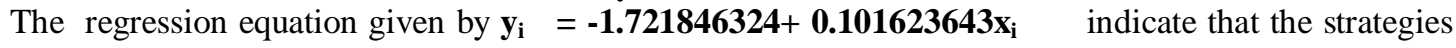
for change management adopted in secondary schools in Nyamira district overtime and the performance in national examinations has a positive relationship $\left(+\mathbf{0 . 1 0 1 6 2 3 6 4 3} \mathbf{x}_{\mathbf{i}}\right)$. The implication is that change management strategies: benchmarking, leadership and motivation strategies do influence the performance in public secondary schools in Kenya. The correlation coefficient $\mathbf{r}=\mathbf{+ 0 . 8 7 7 6 8 6 5 1 6}$ suggests that the degree of association between the strategies and performance in national examinations is positively strong.

\section{Conclusion}

Motivation, leadership styles and benchmarking were the key strategies influenced change management towards achieving better performance. Motivation strategies facilitated change management more followed by benchmarking and leadership styles. Motivation and leadership strategies influenced more the performance in National Examinations in Kisii County. These study findings reveal that change management strategies for performance in public secondary schools originate from motivation, leadership and benchmarking adopted to achieve the set objectives.

\section{Recommendations}

The schools should embrace the use of motivation, benchmarking and good leadership styles to achieve the higher level of performance in national examinations.

\section{References}

[1]. Ackoff R.L. (1989). The Circular Organization: An Update. Academy of Management Executive

[2]. Bowen H.K, Clark K.B, Holloway CA, Wheelwright S.C. (1994). Projects Studied by the Manufacturing Vision Group. Harvard Business Review .

[3]. Campion MA, Medsker GJ, Higgs AC. (1993). Relations between work group characteristics and effectiveness: implications for designing effective work groups. Personnel Psychology 46(4): 823-850

[4]. Clark K.B, Wheelwright S.C. (1993). Managing new product and process development. Free Press: New York

[5]. Cusumano M.A, Nobeoka K. 1992. Strategy, structure and performance in product development: Observations from the auto industry. Research Policy 21(3): 265

[6]. Dai, C.X., Wells W.G. (2004). An exploration of project management office features and their relationship to project performance. International Journal of Project Management

[7]. De Brentani U. (1989). Success and Failure in New Industrial Services. Journal of Product Innovation Management 6(4): 239

[8]. Frey, B.S. (1997). On the relationship between intrinsic and extrinsic work motivation. International Journal of Industrial Organization 15(4): 427

[9]. Gottschal, O., Zollo M. (2006). Motivation and the theory of the firm. Cahier de Recherche RP 68/833: 43p

[10]. Gottschalg O, Zollo M. (2007). Interest alignment and competitive advantage. Academy of Management Review 32(2): 418-437

[11]. Henri J-F. (2006a). Management control systems and strategy: A resource-based perspective. Accounting, Organizations and Society 31: $529-558$

[12]. Herzberg Fa. (1987). One more time: How do you motivate employees? Harvard Business Review 65(5): 109-120

[13]. Hoegl M, Ernst H, Proserpio L. (2007). How Teamwork Matters More as Team Member Dispersion Increases. Journal of Product Innovation Management 24(2): 156-165

[14]. Litunya R.A (2000): benchmarking and Performance in Public Secondary schools in Nairobi in Nairobi Province

[15]. Pascale, R. (1999): Extract from Complexity and the unconscious, in J. Henry, Creativity ,Innovation and Change Media Book, Milton Keynes: Open University Press, pp. 9-10.

[16]. Senge, P. (1999) The Dance of Change, Currency Doubleday, New York 